\title{
Truck Dispatching Optimization Model and Algorithm Based on 0-1 Decision Variables
}

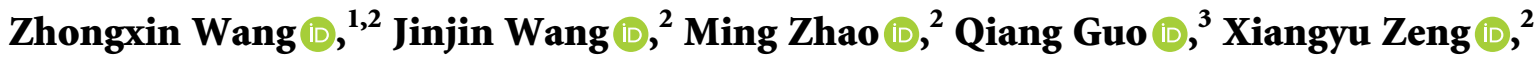 \\ Fengyang Xin $\mathbb{D}^{2}$, and Hao Zhou $\mathbb{D}^{2}$ \\ ${ }^{1}$ School of Mining, Liaoning Technical University, Fuxin, China \\ ${ }^{2}$ Research and Design Centre, CCTEG Shenyang Engineering Company, Shenyang, China \\ ${ }^{3}$ Open-Pit Mine Engineering Business Unit, CCTEG Shenyang Engineering Company, Shenyang, China
}

Correspondence should be addressed to Ming Zhao; 1049323882@qq.com and Qiang Guo; g25893931@163.com

Received 4 January 2022; Accepted 31 January 2022; Published 17 February 2022

Academic Editor: Xiaoshuang Li

Copyright (C) 2022 Zhongxin Wang et al. This is an open access article distributed under the Creative Commons Attribution License, which permits unrestricted use, distribution, and reproduction in any medium, provided the original work is properly cited.

\begin{abstract}
This study established a truck dispatching model adopting 0-1 decision variables to rationally allocate truck transportation in open-pit mines, maximize the total loading and unloading volume of trucks, and solve the problem of the inability of the truck dispatching model to guide production in open-pit mines because of nonspecific results. The model considers loading and unloading logical relationships, working time constraints, loading and unloading volume constraints, traffic flow constraints, and loading and unloading capacity constraints to maximize the total loading and unloading volume. The operation of trucks between loading and unloading sites is taken as the decision variable. The results show multiple transportation routings of all trucks between loading and unloading sites in working time. Double decision variables are used to solve the expression problem of constraints. The mathematical model is solved using Lingo. The proposed algorithm was then used to optimize the truck dispatching. The application result of the total loading and unloading volume was $10950.6 \mathrm{~m}^{3}$, and the total loading and unloading number was 384 . The optimization result could guide production effectively.
\end{abstract}

\section{Introduction}

System optimization is a part of mine intelligent construction [1-3]. In the face of a changing market form, optimizing the production process and reducing enterprise costs are the key issues that each mining enterprise needs to solve urgently [4-7]. Ore and rock transport in open pits is one of the most important links in the open-pit mining process. Transport cost generally accounts for $50 \%-60 \%$ of the total production cost of open-pit mines, and the proportion of the transport cost in some deep and large open-pit mines has exceeded $60 \%$ [8].

At present, most high-yield coal mines are open-pit mining enterprises, mainly using the excavator-truck mining process, and truck transportation plays an important role in open-pit mining enterprises. In the domestic main openpit coal, mining and stripping volume by truck transportation completes the project accounts for about $80 \%$. Therefore, optimizing truck dispatching is the most effective way to reduce the production cost and improve the efficiency of mining enterprises $[9,10]$. Its essence is to allocate trucks reasonably to ensure the efficient operation of production plans [11].

At present, the nonproduction time of trucks in the production shifts of open-pit coal mines exceeds $30 \%$, so there is still a lot of room for the optimization of truck dispatching in open-pit coal mines [12]. Whether the traffic flow allocation is reasonable or not directly affects the economic benefit and production efficiency of open-pit mining enterprises. Therefore, it is particularly important to establish a reasonable truck transportation dispatching model using an efficient algorithm to optimize and solve the problem and then formulate a truck dispatching plan to meet the actual production needs of the mine. Truck 
dispatching optimization in open-pit mines is of great significance for improving truck transportation efficiency and reducing transportation cost.

Many experts and scholars have done a lot of research on truck dispatching in open-pit mines. In foreign countries, White et al. proposed the two-stage model method of traffic flow planning and dynamic assignment of trucks [13-15]. Sgurev et al. discussed the closed-circuit system and opencircuit system as two dynamic truck dispatching systems [16]. Bastos used SimEvents to do a simulation modeling of a dispatching scheme at a turn of the shift to optimize truck assignment and increase production [17]. Subtil et al. applied linear programming to make a traffic flow plan and combined dynamic programming with computational simulation and multiobjective optimization technology to make optimal dispatching decisions for real-time truck dispatching [18]. Souza et al. proposed a hybrid heuristic algorithm that combines the greedy random adaptive search program and a general variable neighborhood search to optimize the minimum sending problem in truck dispatching [19]. Chaowasakoo et al. used MATLAB to conduct simulation modeling and compared the output of each dispatching algorithm under the action of different truckexcavator ratios [20]. Ercelebi and Bascetin proposed an optimization strategy for selecting the number and dispatching of trucks of the same type [21]. Godoy and Dimitrakopoulos developed a combinatorial optimization algorithm based on the simulated annealing algorithm to solve the truck dispatching decision problem [22]. Coelho et al. proposed three multiobjective heuristic algorithms, 2PPLS-VNS, MOVNS, and NSGA-II, which can be applied to the dynamic assignment problem of truck in open-pit mining operations [23]. Mendes et al. proposed a multiobjective evolutionary algorithm that can be applied to the truck dynamic dispatching in open-pit mines and verified that it provided a good solution for all dispatching situations in most cases [24].

In the domestic aspect, experts and scholars have put forward a general traffic flow mathematical model for the needs of a fixed truck, fixed type, fixed unloading point, and optimized flexible assignment of the truck for various matches of hauling fleets and materials and have discussed the differences of independent applications in various situations $[25,26]$. The influence of the section traffic flow and passage capacity was considered, and the concept of comprehensive road resistance was introduced to establish the equilibrium distribution model of traffic flow on a road network for traffic flow of the open-pit [27]. Based on the results of traffic flow planning, the influence of random factors in the system and the transportation distance of trucks were fully considered, and the overall optimization of real-time dispatching was realized based on the completion of a production target and the truck flow saturation [28]. The real-time truck dispatching model was proposed for strip mines based on the target flow saturation of traffic flow planning [29]. The optimization model of truck dispatching was established, and the optimal dispatching scheme was obtained by using the idea of truck formation transportation, truck transfer transportation, and the greedy algorithm [30]. Taking the lowest total transportation cost as the objective function and considering the constraints of ore production, grade balance, and the shortest waiting time for trucks, the quantum particle swarm optimization algorithm was improved to solve the dispatching model [31]. The truck dispatching system model of open-pit mine was established based on FlexSim software [32]. The method of the truck dispatching decision based on the fuzzy decision model was proposed [33]. The multiobjective function dispatching model with the least loss of truck transportation was established, and the genetic algorithm was used to solve the scheduling scheme [12]. The mathematical model of truck dispatching in a semicontinuous process system of coal mining was established to realize the optimal matching between truck and crushing station [34].

The traffic flow planning model or truck dispatching model established by existing studies takes traffic flow, namely, transportation volume, as the decision variable, or the number of truck transportation operations between loading positions and unloading sites as the decision variable. Therefore, the optimization results cannot determine the specific operation status of trucks.

The truck dispatching model established in this study takes the operation of trucks between loading and unloading sites as the decision variables and adopts $0-1$ variables. The target value of the model is the maximum number of truck loadings and unloadings. The loading and unloading logical relationships, working time constraints, loading and unloading volume constraints, traffic flow constraints, and loading and unloading capacity constraints are considered, and two decision variable sets are introduced. The solution results can be used to determine the specific routings of multiple transportations between loading and unloading sites during working time.

\section{Materials and Experiments}

2.1. Truck Dispatching Model. Open-pit truck scheduling adopts the simulation method to verify the truck dispatching scheme and simulate the actual production, which can improve the rationality of production arrangement and reduce the investment. Open-pit trucks are transported back and forth between loading and unloading sites under the command of the dispatching system to maximize the output by using existing equipment resources or minimize the utilization rate of equipment under a certain output. There are two ways to determine the downstream destination after truck loading and unloading are complete. One is to determine the downstream destination according to the fixed assignment scheme of the truck as obtained from traffic flow planning. The second is to determine the downstream destination according to specific, real-time dispatching criteria (such as maximum truck method or maximum shovel method). The truck dispatching model established in this study aims to maximize the output and determine the loading and unloading site according to the traffic flow planning.

The truck dispatching model is a $0-1$ integer programming model; that is, decision variables are 0 or 1 . In order to 
solve the expression problem of constraint conditions, dual decision variables are adopted.

First, 0-1 integer programming is a special form of integer programming, and integer programming is linear programming that restricts all or part of the variables to integer values, which has branched independently from the cutting plane method proposed by R. E. Gomory in 1958. Integer programming is divided into three types: pure integer programming, in which all decision variables are required to be integers; mixed integer programming, in which part of the decision variables must be integers; and 0-1 integer programming, in which the decision variable can only be 0 or 1 . Therefore, it is called the $0-1$ variable.

Moreover, 0-1 integer programming plays an important role in integer programming, and $0-1$ variables can be quantified to describe the logical relationship, order relationship, and mutually exclusive constraints among the discrete variables reflected by the decision of yes or no. All integer programming of bounded variables can be converted into 0 -1 integer programming for processing, and 0-1 integer programming has a wide range of applications, reflecting the convenience and effectiveness of problem solving with $0-1$ variables $[35,36]$. It is a $0-1$ integer programming problem whether or not the stripping position to the internal dumping unit is dumped.

The mathematical model of $0-1$ integer programming is generally expressed as follows:

$$
\begin{aligned}
& \min N=\sum_{j=1}^{n} c_{j} x_{j}, \\
& \text { s.t. } \sum_{j=1}^{n} a x_{j} \leq b_{j}\left(x_{j}=0,1\right) .
\end{aligned}
$$

In the formula, $N$ denotes the target function; $c_{j}$ denotes the value coefficient; $x_{j}$ denotes the decision variable; s.t. denotes the constraints; $a_{j}$ denotes the technical coefficient; $b_{j}$ denotes the right end item.

2.2. Model Thoughts. Truck dispatching in open-pit mines has three aspects: vehicle dispatching, route planning, and operation arrangement. The purpose of vehicle scheduling is to select one or several trucks and arrange loading and unloading sites. Route planning chooses the optimal path from the beginning to the end. Operation arrangement takes into account vehicle speed and waiting time to avoid conflict between vehicles. In order to produce an optimal path, this part needs to be considered simultaneously to deal with the problem.

In this study, there was a path between the single loading and unloading site, and the path operation of different trucks in multiple loading and unloading points was optimized to achieve the maximum truck volume. At the same time, the truck operation had to consider various constraints, such as the safe distance of truck operation, the same starting site and end site of truck loading and unloading between the same and adjacent two times, and the continuity of truck operation times.
2.3. Model Basis. The above constraint restricts that each block can be dumped only once or not at all.

2.3.1. Decision Variables. The number of decision variables is determined by the number of trucks dispatched, the number of loading sites, the number of unloading sites, and the maximum number of loadings and unloadings. The number of trucks, loading sites, and unloading sites can be determined directly. The maximum number of loadings and unloadings is determined by assuming that all trucks were of the type with the smallest loading capacity and the maximum number of times the trucks run between the loading and unloading sites with the smallest road distance or the largest loading and unloading capacity. Determining the maximum loading and unloading times can not only ensure the rationality of the model calculation but also reduce the number of decision variables and constraints and save the calculation time.

2.3.2. Constraint Variables. The variables in the constraint conditions include average loading and unloading volume, average loading and unloading time of the truck, road distance between loading and unloading sites, average speed of the truck, working time, number of pieces of loading equipment, minimum and maximum loading and unloading capacity, truck length, road parking sight distance between loading and unloading sites, and loading and unloading capacity.

The average speed of the truck can be selected according to Table 1 based on the code for design of open-pit mine of coal industry (GB 50197-2015).

Parking sight distance between loading and unloading sites can be selected according to Table 2 based on the standard for design of mine haulage engineering for open-pit in coal industry (GB 51282-2018).

2.4. Model Establishment. The truck scheduling model is expressed as follows.

2.4.1. Objective Function. The solution value of the objective function is the maximum amount of truck loading and unloading.

$$
\max \sum_{i=1}^{I} \sum_{j=1}^{I} \sum_{k=1}^{I} \sum_{l=1}^{I}\left(Q_{i, j} \times X_{i, j, k, l}\right) .
$$

In the formula, $X_{i, j, k, l}$ is the decision variable of whether the truck runs with the number of $i$ from loading site $j$ to unloading site $k$ in the $l$ time, and the value is 0 or $1 ; Q_{i, j}$ is the average loading volume of the truck with the number of $i$ at the loading site $j ; I$ is the number of trucks; $J$ is the number of loading sites; $K$ is the number of unloading sites; $L$ is the maximum number of loadings and unloadings. 
TABle 1: Average speed of truck.

\begin{tabular}{lc}
\hline Haul distance $(\mathrm{km})$ & Truck average speed $(\mathrm{km} / \mathrm{h})$ \\
\hline 0.5 & 14 \\
1.0 & 16 \\
1.5 & 18 \\
2.0 & 20 \\
2.5 & 22 \\
3.0 & 24 \\
3.5 & 25 \\
\hline
\end{tabular}

TABLe 2: Sight distance.

\begin{tabular}{lcccc}
\hline Design speed $(\mathrm{km} / \mathrm{h})$ & 40 & 30 & 20 & 15 \\
Parking sight distance $(\mathrm{m})$ & 50 & 40 & 30 & 20 \\
Meeting sight distance $(\mathrm{m})$ & 100 & 80 & 60 & 40 \\
Back and fore sight distance $(\mathrm{m})$ & 50 & 40 & 30 & 20 \\
\hline
\end{tabular}

2.4.2. Heavy Load Constraint. This restriction limiting the same truck can only do heavy running from the loading site to the unloading site at most once at a time.

$$
\sum_{j=1}^{J} \sum_{k=1}^{K} X_{i, j, k, l} \leq 1, \quad(i=1 \sim I, l=1 \sim L) .
$$

\subsubsection{Empty Load Constraint}

(1) This restriction limiting the same truck can only do empty running from the unloading site to the loading site at most once at a time.

$\sum_{j=1}^{J} \sum_{k=1}^{K} X_{i, j, k, l} \leq 1, \quad(i=1 \sim I, l=1 \sim L-1)$.

In the formula, $X_{i, k, j, l}$ is the decision variable of whether the truck runs with the number of $i$ from unloading site $k$ to loading site $j$ in the $l$ time, and the value is 0 or 1 .

(2) This constraint limits the truck so that it does not return to the loading site after arriving at the unloading site in the maximum amount of time.

$$
\sum_{i=1}^{I} \sum_{j=1}^{J} \sum_{k=1}^{K} X_{i, k, j, L} \leq 0
$$

2.4.4. Unloading Site Constraint. This restriction limiting the end site of heavy running is the same as the beginning site of empty running of the same truck at the same time. In formula (5), the decision variable of empty running is constrained as 0 in the maximum time, and the upper limit value of 1 is $\mathrm{L}-1$ to reduce the number of constraints.

$$
\sum_{j=1}^{J}\left(X_{i, j, k, l}-X_{i, k, j, l}\right) \geq 0, \quad(i=1 \sim I, k=1 \sim K, l=1 \sim L-1) .
$$

2.4.5. Loading Site Constraint. This restriction limiting the beginning site of heavy running is the same as the end site of empty running in the last time of the same truck.

$\sum_{k=1}^{K}\left(X_{i, j, k, l+1}-X_{i, k, j, l}\right) \geq 0, \quad(i=1 \sim I, j=1 \sim J, l=1 \sim L-1)$.

\subsubsection{Working Time Constraint}

(1) This restriction limiting the loading and unloading time of the truck cannot be more than the working time.

$$
\sum_{j=1}^{J} \sum_{k=1}^{K} \sum_{l=1}^{L}\left[X_{i, j, k, l} \times\left(T_{i, j}+\frac{60 S_{j, k}^{1}}{V_{j, k}}+T_{x}\right)+X_{i, k, j, l} \times \frac{60 S_{k, j}^{1}}{V_{k, j}}\right] \leq 60 T, \quad(i=1 \sim I) .
$$

In the formula, $T_{i, j}$ is the average loading time (including waiting time) of the truck with the number of $i$ at the loading site $j ; S_{j, k}^{1}$ is the road distance between the loading site $j$ and unloading site $k ; V_{j, k}$ is the average speed of the truck between loading site $j$ and unloading site $k ; T_{x}$ is the average unloading time (including waiting time) of the truck; $S_{j, k}^{1}$ is the road distance between unloading site $k$ and loading site $j ; V_{k, j}$ is the average speed of the truck between unloading site $k$ and loading site $j ; T$ is the working time.

(2) This constraint limiting the loading time cannot be more than working time.

$\sum_{i=1}^{I} \sum_{k=1}^{K} \sum_{l=1}^{L}\left(X_{i, j, k, l} \times T_{i, j}\right) \leq N_{j} \times 60 T, \quad(j=1 \sim J)$. 
In the formula, $N_{j}$ is the number of pieces of loading equipment at the loading site $j$.

2.4.7. Loading Volume Constraint. This constraint limits the range of the loading volume of the truck at the loading site.

$$
10^{4} Q_{j}^{1} \leq \sum_{i=1}^{I} \sum_{k=1}^{K} \sum_{l=1}^{L}\left(X_{i, j, k, l} \times Q_{i, j}\right) \leq 10^{4} Q_{j}^{2}(j=1 \sim J) .
$$

In the formula, $Q_{j}^{1}$ is the minimum loading volume at the loading site $j ; Q_{j}^{2}$ is the maximum loading volume at the loading site $j$.

2.4.8. Unloading Volume Constraint. This constraint limits the range of the unloading volume of the truck at the unloading site.

$$
10^{4} Q_{k}^{1} \leq \sum_{i=1}^{I} \sum_{j=1}^{J} \sum_{l=1}^{L}\left(X_{i, j, k, l} \times Q_{i, j}\right) \leq 10^{4} Q_{k}^{2}(k=1 \sim K) .
$$

In the formula, $Q_{k}^{1}$ is the minimum unloading volume at the unloading site $k$; $Q_{k}^{2}$ is the maximum unloading volume at the unloading site $j$.

\subsubsection{Loading and Unloading Time Constraints}

(1) This restriction limiting truck transport with a heavy load at this time must also transport with heavy load the last time.

$$
\sum_{i=1}^{I} \sum_{j=1}^{J} \sum_{l=1}^{L}\left(X_{i, j, k, l}-X_{i, j, k, l+1}\right) \geq 0(l=1 \sim L-1) .
$$

(2) This restriction limiting truck transport with an empty load at this time must also transport with an empty load the last time. In formula (5), the decision variable of empty running is constrained as 0 in the maximum time, and the upper limit value of 1 is $\mathrm{L}-1$ to reduce the number of constraints.

$$
\sum_{i=1}^{I} \sum_{j=1}^{J} \sum_{k=1}^{K}\left(X_{i, k, j, l}-X_{i, k, j, l+1}\right) \geq 0(l=1 \sim L-2) .
$$

\subsubsection{Traffic Flow Constraint}

(1) This constraint limits the safe distance requirements for the heavy load truck.

$$
\begin{aligned}
& \sum_{i=1}^{I}\left[X_{i, j, k, l} \times\left(S_{i}+S_{j, k}^{2}\right)\right] \\
& \leq 10^{3} S_{j, k}^{1}(j=1 \sim J, k=1 \sim K, l=1 \sim L) .
\end{aligned}
$$

In the formula, $S_{i}$ is the length of truck; the number is I; $S_{j, k}^{2}$ is the parking sight distance between loading site $j$ and unloading site $k$.
(2) This constraint limits the safe distance requirements for an empty load truck.

$$
\begin{gathered}
\sum_{i=1}^{I}\left[X_{i, k, j, l} \times\left(S_{i}+S_{k, j}^{2}\right)\right] \leq 10^{3} S_{k, j}^{1} \\
(j=1 \sim J, k=1 \sim K, l=1 \sim L) .
\end{gathered}
$$

In the formula, $S_{k, j}^{2}$ is the parking sight distance between unloading site $k$ and loading site $j$.

\subsubsection{Capacity Constraint}

(1) This constraint limits the number of trucks to be loaded at the loading site at a single time.

$$
\sum_{i=1}^{I} \sum_{k=1}^{K}\left(X_{i, j, k, l} \times Q_{i, j}\right) \leq Q_{j}(j=1 \sim J, l=1 \sim L) .
$$

(2) This constraint limits the number of trucks to be unloaded at the unloading site at a single time.

$\sum_{i=1}^{I} \sum_{j=1}^{J}\left(X_{i, j, k, l} \times Q_{i, j}\right) \leq Q_{k}(k=1 \sim K, l=1 \sim L)$. site $k$.

In the formula, $Q_{k}$ is the unloading capacity of unloading

2.5. Model Solution. According to the mathematical model of truck dispatching, model programming and the solution can be carried out in Lingo software. Lingo software is a common software to solve optimization problems, but it can also be used to solve linear programming, nonlinear programming, integer programming, $0-1$ integer programming, and other mathematical programming models. The program language is highly intuitive. Decision variables in Lingo software can be allowed to be integers (i.e., integer programming, including 0-1 integer programming), which is convenient, flexible, and very fast to execute. Lingo software also provides interfaces to other files, making it easy to input, solve, and analyze large-scale optimization problems.

The model programming solution includes the set segment, data segment, and target constraint segment.

The set segment programming statement consists of four basic sets: the truck set, the loading site set, the unloading site set, and the loading and unloading number set. A derived set is composed of basic sets. Two four-dimensional derived sets represent decision variables. The six two-dimensional derived sets represent the average loading volume and time of the truck at the loading site, the road distance and average speed of the truck between the loading and unloading site, the road distance, and the average speed of the truck between the unloading and loading site. According to the mathematical formula of constraint conditions, some other derived sets are generated, which do not represent variables but only facilitate the programming of the sum range and subscript range of the software target constraint segment. 
TABLE 3: Relevant variables of loading and unloading sites.

\begin{tabular}{lcccc}
\hline Loading or unloading site & Loading site 1 & Loading site 2 & Unloading site 1 & Unloading site 2 \\
\hline Average loading volume $\left(\mathrm{m}^{3}\right)$ & 29.6 & 27.4 & - & - \\
Average loading or unloading volume $(\mathrm{min})$ & 3.5 & 4.5 & 3.5 & - \\
Loading equipment number & 2 & 2 & 0.5 & - \\
Minimum loading or unloading volume $\left(10,000 \mathrm{~m}^{3}\right)$ & 0.5 & 0.3 & 1.0 & 0.5 \\
Maximum loading or unloading volume $\left(10,000 \mathrm{~m}^{3}\right)$ & 1.0 & 274 & 296 & 296 \\
Loading or unloading capacity $\left(\mathrm{m}^{3}\right)$ & 296 & & & \\
\hline
\end{tabular}

TABLE 4: Relevant variables between loading and unloading sites.

\begin{tabular}{|c|c|c|c|c|}
\hline $\begin{array}{l}\text { Between loading and } \\
\text { unloading sites }\end{array}$ & $\begin{array}{c}\text { Loading site } 1 \text { to unloading } \\
\text { site } 1<>\end{array}$ & $\begin{array}{c}\text { Loading site } 1 \text { to unloading } \\
\text { site } 2<>\end{array}$ & $\begin{array}{c}\text { Loading site } 2 \text { to unloading } \\
\text { site } 1<>\end{array}$ & $\begin{array}{c}\text { Loading site } 2 \text { to } \\
\text { unloading site } \\
2<>\end{array}$ \\
\hline Road distance $(\mathrm{km})$ & 3.5 & 3.3 & 3.2 & 3.0 \\
\hline Average truck speed $(\mathrm{km} / \mathrm{h})$ & 25 & 25 & 24 & 24 \\
\hline Parking sight distance $(\mathrm{m})$ & 40 & 40 & 40 & 40 \\
\hline
\end{tabular}

TABLE 5: Loading and unloading volume between the loading and unloading sites.

\begin{tabular}{lcccccc}
\hline \multirow{2}{*}{ Loading or unloading site } & \multicolumn{2}{c}{ Loading site 1} & \multicolumn{2}{c}{ Loading site 2} & \multicolumn{2}{c}{ Total } \\
& Num & Volume $\left(\mathrm{m}^{3}\right)$ & Num & Volume $\left(\mathrm{m}^{3}\right)$ & Num & Volume $\left(\mathrm{m}^{3}\right)$ \\
\hline Unloading site 1 & 73 & 2160.8 & 122 & 3342.8 & 195 & 5503.6 \\
Unloading site 2 & 122 & 3611.2 & 67 & 1835.8 & 189 & 5447.0 \\
Total & 195 & 5772.0 & 189 & 5178.6 & 384 & 10950.6 \\
\hline
\end{tabular}

The data segment programming statements assign the number of trucks, the number of loading and unloading sites, and the number of loadings and unloadings (the constraints need not be modified when the number of trucks and other numbers are modified).

The target constraint segment defines 0-1 decision variables. The average loading volume and time of truck at loading site, road distance, average speed of the truck between the loading and unloading site, road distance, and average speed of the truck between the unloading and loading site are assigned. The constraints and objective functions are programmed.

The model should be run to get the optimal solution and the assignment of 0 or 1 to the decision variable. Depending on the assignment of the decision variable 0 or 1 , an assignment of 1 indicates that the truck in this number has been unloaded from the loading site to the unloading site or returned from the unloading site to the loading site. The results can show multiple transportation routings of all trucks between the loading and unloading sites in working time.

\section{Results and Discussion}

3.1. Basic Data. The above constraint restricted that each block could be dumped only once or not at all.

3.1.1. Decision Variables. The number of trucks was 20, the number of loading sites was two, the number of unloading sites was two, and the maximum number of loadings and unloadings was 20 . The trucks were of the same type.

3.1.2. Constraint Variables. The relevant variables of loading and unloading sites are shown in Table 3.

The relevant variables between the loading and unloading sites are shown in Table 4.

For other constraint variables, the working time was $8 \mathrm{~h}$, and the truck length was $10.3 \mathrm{~m}$.

3.2. Solution Results. The set segment programming statements of the Lingo software had four basic sets. The number of elements in the truck set was 20 . The number of elements in the loading site set was two. The number of elements in the unloading site set was two. The number of elements in the loading and unloading number set was 20 . The derived sets were programmed to represent variables and were used for constraint programming statements.

The data segment programming statements assigned the number of trucks to 20 , the number of loading sites to two, the number of unloading sites to two, and the maximum number of loadings and unloadings to 20 .

In the target constraint segment, the decision variable value of 0 or 1 was defined. The average loading volume and time of the truck were assigned to distinguish loading sites. The road distance from the loading site to the unloading site, the average speed of the truck, the road distance from the unloading site to the loading site, and the average speed of the truck were directly assigned. The constraint conditions 
TABLE 6: Truck loading and unloading volume.

\begin{tabular}{|c|c|c|c|c|c|}
\hline \multirow{2}{*}{$\begin{array}{l}\text { Truck } \\
\text { number }\end{array}$} & \multicolumn{5}{|c|}{ Loading and unloading volume $\left(\mathrm{m}^{3}\right)$} \\
\hline & $\begin{array}{c}\text { Loading site } 1 \text { to unloading } \\
\text { site } 1<>\end{array}$ & $\begin{array}{c}\text { Loading site } 1 \text { to unloading } \\
\text { site } 2<>\end{array}$ & $\begin{array}{l}\text { Loading site } 2 \text { to unloading } \\
\text { site } 1<>\end{array}$ & $\begin{array}{c}\text { Loading site } 2 \text { to unloading } \\
\text { site } 2<>\end{array}$ & Total \\
\hline 1 & 296.0 & 88.8 & 191.8 & 0.0 & 576.6 \\
\hline 2 & 88.8 & 177.6 & 82.2 & 191.8 & 540.4 \\
\hline 3 & 0.0 & 266.4 & 274.0 & 0.0 & 540.4 \\
\hline 4 & 29.6 & 414.4 & 54.8 & 54.8 & 553.6 \\
\hline 5 & 0.0 & 325.6 & 137.0 & 82.2 & 544.8 \\
\hline 6 & 29.6 & 266.4 & 137.0 & 109.6 & 542.6 \\
\hline 7 & 325.6 & 118.4 & 137.0 & 0.0 & 581.0 \\
\hline 8 & 236.8 & 29.6 & 301.4 & 0.0 & 567.8 \\
\hline 9 & 59.2 & 59.2 & 301.4 & 109.6 & 529.4 \\
\hline 10 & 118.4 & 296.0 & 82.2 & 54.8 & 551.4 \\
\hline 11 & 0.0 & 266.4 & 164.4 & 109.6 & 540.4 \\
\hline 12 & 0.0 & 177.6 & 191.8 & 164.4 & 533.8 \\
\hline 13 & 0.0 & 0.0 & 0.0 & 493.2 & 493.2 \\
\hline 14 & 0.0 & 266.4 & 246.6 & 27.4 & 540.4 \\
\hline 15 & 236.8 & 29.6 & 301.4 & 0.0 & 567.8 \\
\hline 16 & 355.2 & 59.2 & 137.0 & 27.4 & 578.8 \\
\hline 17 & 29.6 & 177.6 & 164.4 & 164.4 & 536.0 \\
\hline 18 & 0.0 & 177.6 & 164.4 & 164.4 & 506.4 \\
\hline 19 & 355.2 & 88.8 & 137.0 & 0.0 & 581.0 \\
\hline 20 & 0.0 & 325.6 & 137.0 & 82.2 & 544.8 \\
\hline Total & 2160.8 & 3611.2 & 3342.8 & 1835.8 & 10950.6 \\
\hline
\end{tabular}

TABLE 7: Transportation routings of the truck.

\begin{tabular}{|c|c|c|c|c|}
\hline Loading and unloading number & Loading site 1 & Loading site 2 & Unloading site 1 & Unloading site 2 \\
\hline 1 & 0 & & 0 & \\
\hline 2 & O & & O & \\
\hline 3 & & O & O & \\
\hline 4 & O & & O & \\
\hline 5 & & O & O & \\
\hline 6 & & O & O & \\
\hline 7 & & O & O & \\
\hline 8 & O & & & O \\
\hline 9 & & O & O & \\
\hline 10 & ○ & & & O \\
\hline 11 & O & & & O \\
\hline 12 & & O & O & \\
\hline 13 & O & & $\mathrm{O}$ & \\
\hline 14 & O & & O & \\
\hline 15 & $\mathrm{O}$ & & $\mathrm{O}$ & \\
\hline 16 & O & & O & \\
\hline 17 & & $\mathrm{O}$ & $\mathrm{O}$ & \\
\hline 18 & O & & O & \\
\hline 19 & O & & 0 & \\
\hline 20 & 0 & & 0 & \\
\hline
\end{tabular}

were programmed (using logical symbols to limit the range of subscripts), and the target function was programmed.

The optimal solution of the model was $10950.6 \mathrm{~m}^{3}$. The trucks ran 73 times from loading site 1 to unloading site 1 , and the transport volume was $2160.8 \mathrm{~m}^{3}$. The trucks ran 122 times from loading site 1 to unloading site 2 , and the transport volume was $3611.2 \mathrm{~m}^{3}$. The trucks ran 122 times from loading site 2 to unloading site 1 , and the transport volume was $3342.8 \mathrm{~m}^{3}$. The trucks ran 67 times from loading site 2 to unloading site 2, and the transport volume was $1835.8 \mathrm{~m}^{3}$.

Loading site 1 was loaded with 195 trucks, and the loading volume was $5772.0 \mathrm{~m}^{3}$. Loading site 2 was loaded with 189 trucks, and the loading volume was $5178.6 \mathrm{~m}^{3}$. Unloading site 1 was unloaded with 195 trucks, and the unloading volume was $5503.6 \mathrm{~m}^{3}$. Unloading site 2 was unloaded with 189 trucks, and the unloading volume was $5447.0 \mathrm{~m}^{3}$. A total of 384 trucks were loaded and unloaded. 
The loading and unloading volumes between the loading and unloading sites are shown in Table 5.

The truck loading and unloading volume are shown in Table 6 .

Taking truck number 1 as an example, $\bigcirc$ represents the specific routings of the truck between the loading and unloading site, as shown in Table 7.

\section{Conclusions}

(1) In view of the problem that the truck dispatching model results of open-pit mines are not specific and cannot guide production, a truck dispatching model with double $0-1$ decision variables was established by taking whether the truck runs between loading and unloading sites as the decision variables to maximize the total loading and unloading volume.

(2) The model determines the maximum loading and unloading times in advance to save the operation time and considers loading and unloading logical relationships, working time constraints, loading and unloading volume constraints, traffic flow constraints, and loading and unloading capacity constraints. The optimization results show multiple transportation routings of all trucks between loading and unloading sites in working time.

(3) The algorithm was used to optimize the truck dispatching, and the results showed that the maximum loading volume was $10950.6 \mathrm{~m}^{3}, 384$ trucks were loaded and unloaded, and specific transportation routings of the trucks. The optimization result could guide production effectively [37].

\section{Data Availability}

The data used to support the findings of this study are included within the article.

\section{Conflicts of Interest}

Ming Zhao was employed by CCTEG Shenyang Engineering Company. The remaining authors declare that the research was conducted in the absence of any commercial or financial relationships that could be construed as potential conflicts of interest.

\section{Authors' Contributions}

Zhongxin Wang and Ming Zhao wrote the original draft and performed the calculation and analysis. Jinjin Wang and Xiangyu Zeng contributed to the conceptualization. Qiang Guo was responsible for the writing of the original draft. Fengyang Xin and Hao Zhou reviewed and edited the manuscript.

\section{Acknowledgments}

This work was supported by the Science and Technology Innovation Venture Capital Special Foundation of China
Coal Technology \& Engineering Group (no. 2018-2-ZD004). The authors wish to acknowledge these supports.

\section{References}

[1] X. Li, Z. Liu, and S. Yang, "Similar physical modeling of roof stress and subsidence in room and pillar mining of a gently inclined medium-thick phosphate rock," Advances in Civil Engineering, vol. 202117 pages, 2021.

[2] X. Li, S. Yang, Y. Wang, W. Nie, and Z. Liu, "Macro-micro response characteristics of surrounding rock and overlying strata towards the transition from open-pit to underground mining," Geofluids, vol. 202118 pages, 2021.

[3] X. Li, Q. Li, and Y. Hu, "Evolution characteristics of mining fissures in overlying strata of stope after converting from open-pit to underground," Arabian Journal of Geosciences, vol. 14 , no. 24 , pp. $1-18,2021$.

[4] X. Li, K. Peng, J. Peng, and D. Hou, "Effect of thermal damage on mechanical behavior of a fine-grained sandstone," Arabian Journal of Geosciences, vol. 14, no. 13, 2021.

[5] X. Li, K. Peng, J. Peng, and H. Xu, "Effect of cyclic wettingdrying treatment on strength and failure behavior of two quartz-rich sandstones under direct shear," Rock Mechanics and Rock Engineering, vol. 54, no. 11, pp. 5953-5960, 2021.

[6] J. Geng, Q. Li, X. Li et al., "Research on the evolution characteristics of rock mass response from open-pit to underground mining," Advances in Materials Science and Engineering, vol. 2021, pp. 1-15, 2021.

[7] X. Li, K. Peng, J. Peng, and D. Hou, "Experimental investigation of cyclic wetting-drying effect on mechanical behavior of a medium-grained sandstone," Engineering Geology, vol. 293, no. 293, Article ID 106335, 2021.

[8] Z. X. Wang, M. Zhao, J. J. Wang, Q. J. Su, and X. Y. Zeng, "Study on wiring road parameters optimization of dual-energy truck in open pit mine," Coal Engineering, vol. 52, no. 3, pp. 31-36, 2020.

[9] S. Alarie and M. Gamache, "Overview of solution strategies used in truck dispatching systems for open pit mines," International Journal of Surface Mining, Reclamation and Environment, vol. 16, no. 1, pp. 59-76, 2002.

[10] N. Cetin, Open-pit Truck/shovel Haulage System Simulation, Middle East Technical University, Istanbul, 2004.

[11] L. Zhang and X. Xia, "An integer programming approach for truck-shovel dispatching problem in open-pit mines," Energy Procedia, vol. 75, no. 75, pp. 1779-1784, 2015.

[12] Y. Wang and S. D. Wang, "Research of truck dispatch model based on genetic algorithm," Journal of Changchun Normal University, vol. 34, no. 10, pp. 38-41, 2015.

[13] J. W. White, M. J. Arnold, and J. G. Clevenger, "Automated open-pit truck dispatching at Tyrone," Engineering and Mining Journal, vol. 183, no. 6, pp. 76-84, 1982.

[14] J. W. White and J. P. Olson, "Computer-based dispatching in mines with concurrent operating objectives," Mining Engineering, vol. 38, no. 11, pp. 1045-1054, 1986.

[15] J. W. White, J. P. Olson, and S. I. Vohnout, "On improving truck/shovel productivity in open pit mines," CIM Bulletin, vol. 1993, no. 9, 4 pages, 1993.

[16] V. Sgurev, V. Vassilev, N. Dokev et al., “Trasy - an automated system for real-time control of the industrial truck haulage in open-pit mines," European Journal of Operational Research, vol. 43, no. 1, pp. 44-52, 1989.

[17] G. S. Bastos, "Decision making applied to shift change in stochastic open-pit mining truck dispatching," IFAC Proceedings Volumes, vol. 46, no. 16, pp. 34-39, 2013. 
[18] R. Subtil, D. Silva, and J. Alves, "A practical approach to truck dispatch for open pit mines," in Proceedings of the 35th International Symposium on Application of Computers in the Minerals Industry (35th APCOM), pp. 765-777, NSW: Wollongong, September 2011.

[19] M. J. F. Souza, I. M. Coelho, S. Ribas, H. G. Santos, and L. H. C. Merschmann, "A hybrid heuristic algorithm for the open-pit-mining operational planning problem," European Journal of Operational Research, vol. 207, no. 2, pp. 1041-1051, 2010.

[20] P. Chaowasakoo, H. Seppälä, H. Koivo, and Q. Zhou, "Improving fleet management in mines: the benefit of heterogeneous match factor," European Journal of Operational Research, vol. 261, no. 3, pp. 1052-1065, 2017.

[21] S. G. Ercelebi and A. Bascetin, "Optimization of shovel-truck system for surface mining," Journal of the South African Institute of Mining and Metallurgy, vol. 109, no. 7, pp. 433439, 2009.

[22] M. Godoy and R. Dimitrakopoulos, "Managing risk and waste mining in long-term production scheduling of open-pit mines," SME Transactions, vol. 9, no. 9, pp. 43-50, 2004.

[23] V. N. Coelho, M. J. F. Souza, I. M. Coelho, F. G. Guimaraes, T. Lust, and R. C. Cruz, "Multi-objective approaches for the open-pit mining operational planning problem," Electronic Notes in Discrete Mathematics, vol. 39, no. 2, pp. 233-240, 2012.

[24] J. B. Mendes, M. F. S. V. D'Angelo, N. A. Maia, and R. R. Veloso, "A hybrid multiobjective evolutionary algorithm for truck dispatching in open-pit-mining," IEEE Latin America Transactions, vol. 14, no. 3, pp. 1329-1334, 2016.

[25] X. Y. Sun, F. L. Tian, H. Zhang, and B. Sun, "Traffic flow model in open pit mine for needs of fixed assignment of truck," Journal of China Coal Society, vol. 41, no. S2, pp. 583-588, 2016.

[26] X. Y. Sun and W. G. Zhang, "Traffic flow programming model for various matchs of hauling fleet and materials in open-pit mine," Journal of Northeastern University, vol. 33, no. 10, pp. 1487-1491, 2012.

[27] X. Y. Sun, S. S. Zhao, and H. Zhang, "Equilibrium distribution model of traffic flow on road network for traffic flow of openpit," Journal of China Coal Society, vol. 42, no. 6, pp. 1607-1613, 2017.

[28] J. Xing and X. Y. Sun, "The open-pit truck dispatching method based on the completion of production target and the truck flow saturation," Journal of China Coal Society, vol. 32, no. 5, pp. 477-480, 2007.

[29] Y. Zhao, Y. Zhang, W. L. Xu, and J. Zhang, "A design of realtime truck dispatching model for strip mines based on flow saturation," Mining and Metallurgy, vol. 2004, no. 2, 74 pages, 2004.

[30] H. Y. Liu, Q. C. Ji, M. M. Xu, and L. Jia, “Optimal selection of open-pit mine production truck dispatching," Mining Technology, vol. 12, no. 6, pp. 63-65, 2012.

[31] J. D. Wang, N. Li, Y. H. Wu, W. J. Lu, L. G. Wang, and J. J. Li, "Truck scheduling optimition in open pit mines based improved DCW-QPSO algorithm," Metal Mine, vol. 2019, no. 12, pp. 156-162, 2019.

[32] Yu. Gao and B. Zhao, "A modeling method of truck dispatching systems in the open-pit mine based on," FlexSim. Machinery, vol. 46, no. 11, pp. 58-64, 2019.

[33] W. Geng, J. J. Jia, and E. Z. Liang, "Open-pit mine truck scheduling fuzzy decision making system," Guangdong Chemical Industry, vol. 44, no. 13, pp. 319-320, 2017.
[34] H. M. Bao and S. R. Wang, "Mathematical model of truck scheduling for semi-continuous coal mining process system," Coal Technology, vol. 38, no. 6, pp. 136-139, 2019.

[35] X. Y. Sun, P. H. Deng, and M. Zhao, "Integrated optimization model of multi-period open-pit mine production scheduling," Journal of Northeastern University, vol. 37, no. 10, pp. 14601464, 2016.

[36] M. Zhao, Short-term Production Scheduling's Integrative Optimization and Application in Yimin NO.3 Open Pit, Northeastern University, Shenyang, 2014.

[37] Q. Wang, Y. Zhang, and C. Chen, "Open-pit mine truck realtime dispatching principle under macroscopic control," in Proceedings of the International Conference on Innovative Computing, Information and Control, IEEE, Beijing, China, August 2006. 